\title{
Numerical Analysis of Thermal Environment in Deep Mining
}

\author{
Qi Li $\mathbb{D},{ }^{1}$ Shuang You $\mathbb{D}^{1,2}$ HongGuang Ji, ${ }^{1,2}$ Huici Xu, ${ }^{1}$ and Huan Wang ${ }^{1}$ \\ ${ }^{1}$ University of Science and Technology Beijing, School of Civil and Resource Engineering, Beijing 10083, China \\ ${ }^{2}$ Beijing Key Laboratory of Urban Underground Space Engineering, USTB, Beijing 10083, China \\ Correspondence should be addressed to Shuang You; youshuang@ustb.edu.cn
}

Received 30 July 2021; Accepted 21 October 2021; Published 17 November 2021

Academic Editor: Xing Li

Copyright (c) 2021 Qi Li et al. This is an open access article distributed under the Creative Commons Attribution License, which permits unrestricted use, distribution, and reproduction in any medium, provided the original work is properly cited.

\begin{abstract}
To analyze heat effect in deep metal mines, it is crucial to understand the temperature field distribution around the mine tunnel. In this paper, a numerical model of the random mineral composition of the rock body is established based on finite element software to analyze the influence of the internal composition of the surrounding rock on the temperature field, and a numerical simulation model based on COMSOL finite element software is established based on the two heat exchange modes of heat conduction and heat convection in the surrounding rock. The results show that the numerical simulation results of a typical numerical simulation model using a single material are lower than the real situation; increasing the tunnel length does not increase the heat exchange efficiency between the rock wall and the air; increasing the wind velocity has a limited impact on the temperature field; the wind temperature more directly affects the mining surface; and the effect of wet air on the temperature field of the surrounding rock has a more substantial variation.
\end{abstract}

\section{Introduction}

Shallow mineral resources are becoming increasingly rare, and deep mining is attracting domestic and international attention $[1,2]$. The current mining depth is expanding at a pace of 8-12 meters per year on average. The temperature of the subsurface rock layer rises with depth, having a $3^{\circ} \mathrm{C} /$ $100 \mathrm{~m}$ average ground temperature differential. The Xiling mining section of the Shandong Sanshandao gold mine will reach a depth of more than 2000 meters, with temperatures reaching 60 degrees Celsius. Hot and humid conditions can affect the productivity of underground workers [3], which can lead to lower production. Therefore, the climatic conditions in underground mines must remain safe.

Scholars in elsewhere have undertaken numerous studies on the dispersion of temperature fields in the tunnel's surrounding rock. Krarti and Kreider [4] proposed a model for the calculation of temperature magnitude and average temperature in underground tunnels. Xia [5] et al. used the separation variable method and the Laplace integral transformation principle to obtain an explicit analytical solution of the transient temperature field in the tunnel. Xin et al. [6] conducted numerical simulations on the effects of factors such as cross-sectional shape of the tunnel, rock surface roughness, and gas Reynolds number during excavation, and the study showed that the Reynolds number has the greatest effect on convective heat transfer coefficient and wall temperature. Zhou et al. [7] used the transient heat transfer model coupled with convection and conduction to study the dynamic changes of the temperature field during the operation of the tunnel. Lu [8] established a three-dimensional numerical model of convective heat transfer using model test results and field data to verify the evaluation of factors affecting the temperature of the surrounding rock. Liu [9] investigated the distribution law of the tunnel temperature field under different inlet temperatures and wind speeds through model tests and verified the correctness of the frost front control equation. By studying the periodic changes of the temperature field inside the surrounding rock, Heist[10], a German scholar, proposed the initial theory about the heat-regulating circle of the surrounding rock. Nottrot [11], a German scholar, described the temperature field of the heat-regulating circle of the surrounding rock using the numerical calculation method. Shuguang Zhang used MATLAB software to numerically solve the temperature field of the surrounding rock in the deeply buried tunnel and 
obtain the temperature field distribution. Lai [12] used ANSYS finite element software to calculate the distribution of the temperature field of the surrounding rock and compared it with the factorless analytical formula of the temperature field of the surrounding rock subjected to different wind flow cooling times, and the results were very similar. Zhang [13] used the FISH language in FLAC3D3.0 to write a program to simulate the temperature field with and without seepage to compare and contrast, and the results showed that disregarding the effect of seepage would exaggerate the thickness of the freeze-thaw circle results.

\section{Materials and Methods}

2.1. Alleyway Heat Transfer Theory. The heat from the deep section of the rock body and the heat dispersed from the rock itself maintain an equilibrium state before the mine tunnel is dug, thus the rock temperature remains constant, and the rock temperature at this moment is the original rock temperature. This thermal balance is disturbed, and heat exchange happens when the subsurface tunnel is dug and ventilated. The internal temperature of the rock body gradually decreases during this process, and the range of the rock body with reduced temperature continues to extend to the depth until a new thermal equilibrium state is formed, and the part of the shaft surrounding rock surrounded by the boundary that is not affected by wind flow is usually referred to as the heat transfer circle of the shaft surrounding rock [14]. The original rock temperature of the surrounding rock, the thermal and physical qualities of the surrounding rock, the temperature of the wind flow, the speed of the wind flow, and the ventilation duration are the most important influencing factors [15].

Heat dissipation from the tunnel's surrounding rock is a complicated nonstationary process that involves heat conduction within the rock, convective heat exchange between the rock and the wind flow, and thermal radiation in three ways: heat conduction is the transport of heat from the earth to the tunnel's surrounding rock as shown in Figure 1; the heat transfer between the tunnel surrounding rock and the airflow in the mining area is convective heat exchange, as shown in Figure 1; and the heat release from the mining machinery in the mining area and the human body is radiative heat release, while the heat exchange with the airflow in the tunnel also exists. This heat exchange makes the airflow temperature in the tunnel tend to be evenly distributed; for the process shown in Figure 1, this study will look at the tunnel envelope's thermal analysis from these two perspectives, analyzing the tunnel's heat transfer circle and internal temperature field, as well as the affecting elements.

When heat transfer is carried out by a rock heat transfer circle, heat conduction is the most common mode of heat transfer [16], and the thermophysical properties of the rock (thermal conductivity, specific heat capacity, and so on) are the most important characteristic parameters for the study of heat transfer as they directly affect the distribution of the temperature field of the surrounding rock. The mineral composition, porosity, saturation, and other intrinsic influencing factors in the heat transfer calculation of the

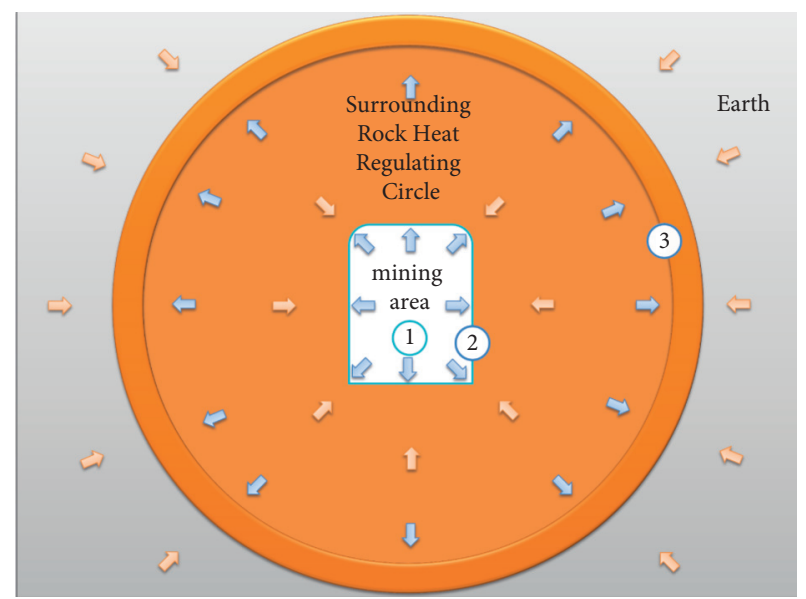

FIGURE 1: Schematic diagram of heat transfer in the heat-regulating circle of the surrounding rock.

surrounding rock are usually the main intrinsic influencing factors, with the mineral composition being the intrinsic primary factor affecting its thermophysical properties [17].

The controlling equation for transient heat conduction in rocks follows Fourier's law [18]:

$$
\rho_{c} \frac{\partial T(x, y, z, t)}{\partial t}=\left(k_{x} \frac{\partial^{2} T}{\partial x^{2}}+k_{y} \frac{\partial^{2} T}{\partial y^{2}}+k_{z} \frac{\partial^{2} T}{\partial z^{2}}\right)+Q(x, y, z, t) .
$$

In equation (1), $Q(x, y, z, t)$ is the internal heat source, $J$; $\rho$ is the density of rock, $\mathrm{kg} / \mathrm{m}^{3} ; c$ is the specific heat capacity of rock, $\mathrm{J} /\left(\mathrm{kg} \cdot{ }^{\circ} \mathrm{C}\right)$; $T$ is the temperature; ${ }^{\circ} \mathrm{C} ; t$ is the time, $s$; and $k_{x}, k_{y}$, and $k_{z}$ are the thermal conductivity in 3 directions, W/ $\left(\mathrm{m} \cdot{ }^{\circ} \mathrm{C}\right)$.

Because the process of heat transfer between the tunnel envelope and the surrounding air is more complicated, an analytical solution is more difficult to acquire; hence, numerical computation methods are utilized to solve:

$$
\rho c_{p} \frac{\partial T}{\partial t}+\rho c_{p} \nabla T+\nabla \cdot(-k \nabla T)=Q+Q_{\text {ted }} .
$$

In equation (2), $\rho$ is the rock density, $\mathrm{kg} / \mathrm{m}^{3} ; c_{p}$ is the heat capacity $\mathrm{J} /(\mathrm{kg} \bullet \mathrm{K}) ; Q$ is the heat source, $W / m$; and $Q_{\text {ted }}$ is the thermal damping, $W / m$. The first term is the time accumulation term, which controls the accumulation of heat during the transient process; the second term is the conduction term, which represents the heat transfer process inside the energy rock; and the third term is the fluid convection term, which represents the process of fluid heat transfer inside the tunnel.

\subsection{Numerical Simulation}

2.2.1. Heat Conduction Model of the Surrounding Rock. The simulation model in this paper is a deep mine surrounding rock, and the mesh is a DCC3D eight-node convection/diffusion hexahedral cell with the size of a cylinder of $25 \mathrm{~m}$ radius, and the initial temperature is $20^{\circ} \mathrm{C}$ and one side is set to $60^{\circ} \mathrm{C}$, with observing the temperature 
change of the surrounding rock. By secondary development of ABAQUS, the material properties of each mineral are randomly distributed in the divided grid according to the percentage of mineral fraction using the weight randomization algorithm. The model is shown in Figure 2. Each rock in the model above represents a distinct mineral component, and the thermal conductivity of several mineral components is listed in Table 1.

The rock sample cores in this research were collected from the shaft engineering region of the Xiling mine in Sanshandao, and the mineral composition of the rock sample specimens was determined using a polarized light microscope test. The results are listed in Table 2.

2.2.2. Heat Convection Model of Surrounding Rock and Air. The simulation model in Figure 3 is a single tunnel, with a width of $4.2 \mathrm{~m}$, a height of $3.4 \mathrm{~m}$, and a standard tunnel length of $30 \mathrm{~m}$. The tunnel length is changed according to different influencing factors below, and the rock calculation range is taken as $20 \mathrm{~m} \times 20 \mathrm{~m} \times 40 \mathrm{~m}$ to meet the heat transfer calculation accuracy requirements. According to the actual observed water temperature in Sanshandao gold mine, the water temperature at $1000 \mathrm{~m}$ depth is $34^{\circ} \mathrm{C}$; hence, the surrounding rock's boundary temperature is $34^{\circ} \mathrm{C}$.

\section{Results and Discussion}

3.1. Analysis of Heat Transfer Results. The comparison results in Figure 4 show that the mineral composition stochastic model has higher temperature in the same time compared with the single composition model in the usual case although the temperature results of the single mineral composition model are smooth and the random weight mineral composition stochastic model is closer to the real situation, and when the grid is small enough, the stochastic model is more responsive to the temperature distribution of the real surrounding rock temperature field, and moreover it can show that the usual numerical simulation model in the numerical simulation results using a single material is small compared with the real situation.

\subsection{Analysis of Convective Results}

\subsubsection{Comparison of Measured Temperatures}

(1). The test components are mainly in the segmented lane, the mining joint lane, and the quarry, and the field test covers the rock temperature and air temperature. Six measurement points were chosen: the first two measurement points in the segmented lane, the third and fourth two measurement points in the mining joint lane, and the fifth and sixth two measurement points inside the quarry, even in the segmented lane with ventilation measures the air flow temperature can still be felt. After entering the quarry, the temperature of the wall surface rises to $32.2^{\circ} \mathrm{C}$, and the temperature and humidity of the air rise as well.
According to the heat transfer model analysis in Figure 5, the simulated wall temperature has a good match with the simulation results, and it is known that the common numerical simulation model utilizing a single material has a tiny numerical simulation result compared with the real scenario. As a result, while the simulated air temperature is numerically lower than the real situation, the overall trend is consistent, and the error with the real temperature is within an acceptable range with some reference value.

(2) Length of Tunnel. Other factors remaining constant, increasing the length of the tunnel did not improve the heat exchange efficiency of the rock wall and air; in a wind speed of $1 \mathrm{~m} / \mathrm{s}$, the limit heat exchange distance is about $25-30 \mathrm{~m}$, as shown in Figure 6. Especially in longer tunnels, the limit heat exchange distance is $30 \mathrm{~m}$ due to the decay of the flow rate, and there is still a high temperature above $30^{\circ} \mathrm{C}$ in the deeper part of the tunnels. So in the later simulation, $30 \mathrm{~m}$ will be the standard tunnel length.

(3) Wind Flow Speed. Figures 7-9 show the performance of wall temperature, air temperature distribution, and its gradient under different wind flow velocities. The results show that as the velocity increases, the degree of heat exchange between the rock wall and air becomes more intense, which shows that the velocity increases and the temperature decreases more along the depth of the tunnel; meanwhile, the greater the velocity, the smaller the temperature gradient at the entrance of the tunnel, the greater the temperature gradient deeper in the tunnel, and the temperature gradient takes an obvious turn at $10 \mathrm{~m}$. When entering the depth of the tunnel, the heat exchange efficiency decays and a greater wind velocity is needed to enhance the heat exchange efficiency, but the results show that when the flow velocity is $3 \mathrm{~m} / \mathrm{s}$ and $4 \mathrm{~m} / \mathrm{s}$, the effect of the wind velocity enhancement on the temperature field is already very limited.

(4) Airflow Humidity. Figures 10-12 depict the performance of the wall temperature and air temperature distributions, as well as their gradients, under various air flow humidity conditions. This paper simulates the analysis using various steam mass fractions, and the results show that as the wind flow humidity increases, the degree of heat exchange between the rock wall and air becomes more intense. The greater the decrease in temperature along the deeper part of the tunnel, the greater the steam mass fraction, and when the air carries a large amount of water vapor, the steam mass fraction is greater than 0.6 , the heat exchange between the rock wall and the air increases dramatically, and the heat is used for water evaporation. Wet air has a comparatively big effect on the temperature field compared with dry air under other parameters that remain constant.

(5) Airflow Temperature. Figure 13-15 depict the performance of the wall and air temperature distributions, as well as their gradients, for various wind flow temperatures. The results show that as the temperature of the wind decreases, the degree of heat exchange between the rock wall and the air 


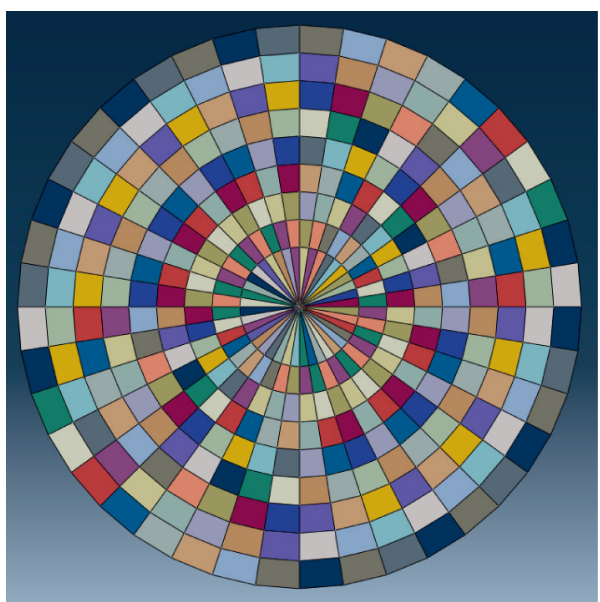

(a)

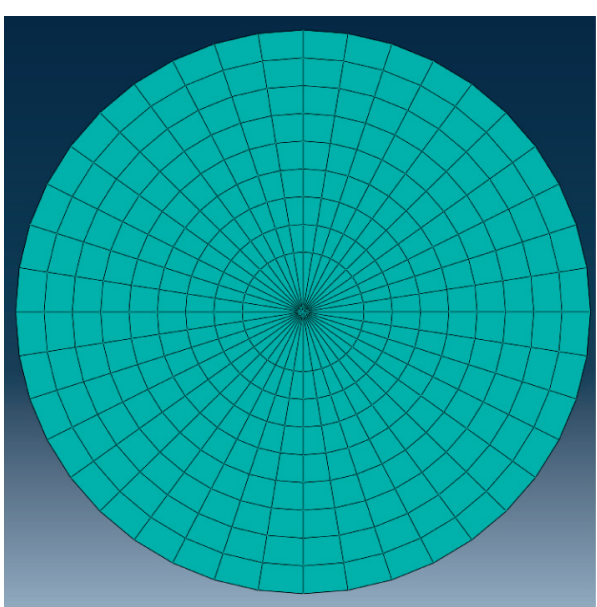

(b)

Figure 2: (a) Random mineral composition model vs. (b) single mineral composition model.

TABLE 1: Thermal conductivity of different mineral compositions.

\begin{tabular}{ccccc}
\hline Conductivity W/(m.K) & Quartz 7.69 & Potassium feldspar 2.37 & Plagioclase 1.87 & Black mica 2.51 \\
\hline & Calcite & Dolomite & White mica & Hornblende \\
& 3.59 & 4.70 & 2.05 & 2.54 \\
& Alkali feldspar & Rock salt & & \\
& 2.30 & 5.60 & & \\
\hline
\end{tabular}

TABLE 2: Composition of rock samples.

\begin{tabular}{|c|c|c|c|c|c|c|c|}
\hline $\begin{array}{l}\text { Laboratory } \\
\text { designation }\end{array}$ & $\begin{array}{c}\text { Potassium feldspar } \\
(\%)\end{array}$ & Plagioclase (\%) & Quartz (\%) & $\begin{array}{l}\text { Black } \\
\text { mica }\end{array}$ & Calcite (\%) & $\begin{array}{c}\text { White mica } \\
(\%)\end{array}$ & Unidentified (\%) \\
\hline $\begin{array}{l}\text { Medium and coarse } \\
\text { grained black cloudy } \\
\text { diorite granite }\end{array}$ & 23 & 36 & 33 & 7 & & & \\
\hline
\end{tabular}
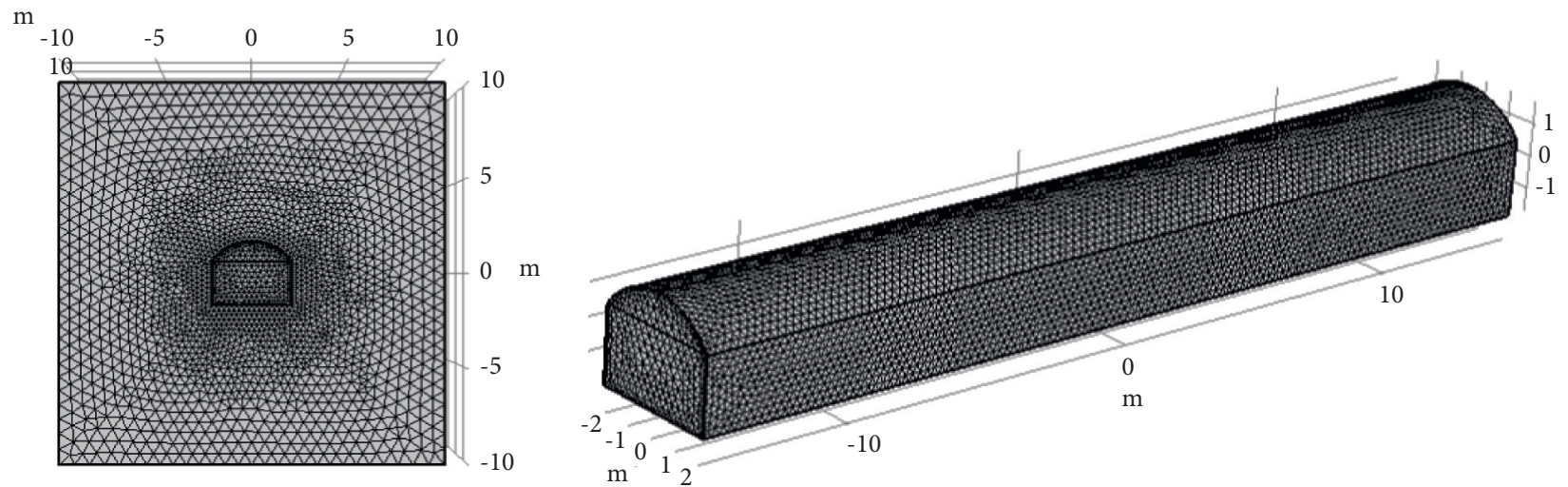

Figure 3: Schematic diagram of the model.

increases, and as the depth of the tunnel increases, the heat exchange efficiency decreases. At 5 meters from the entrance, the wall temperature takes an obvious turn, and the air temperature gradient reaches its maximum at 6 meters. Compared with the effect of velocity and humidity on the temperature field, the effect of air temperature on the 


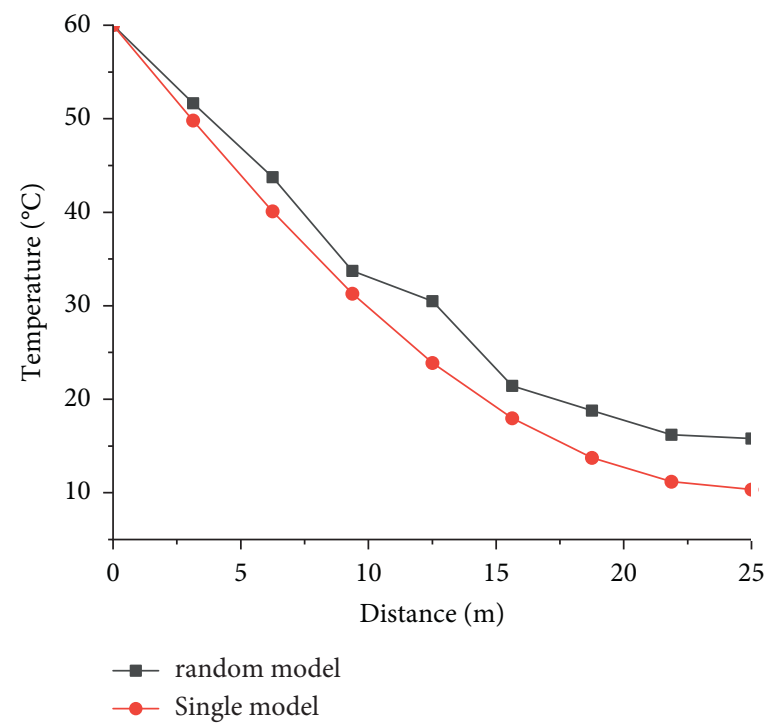

FigURE 4: Single model vs. random model temperature comparison chart.

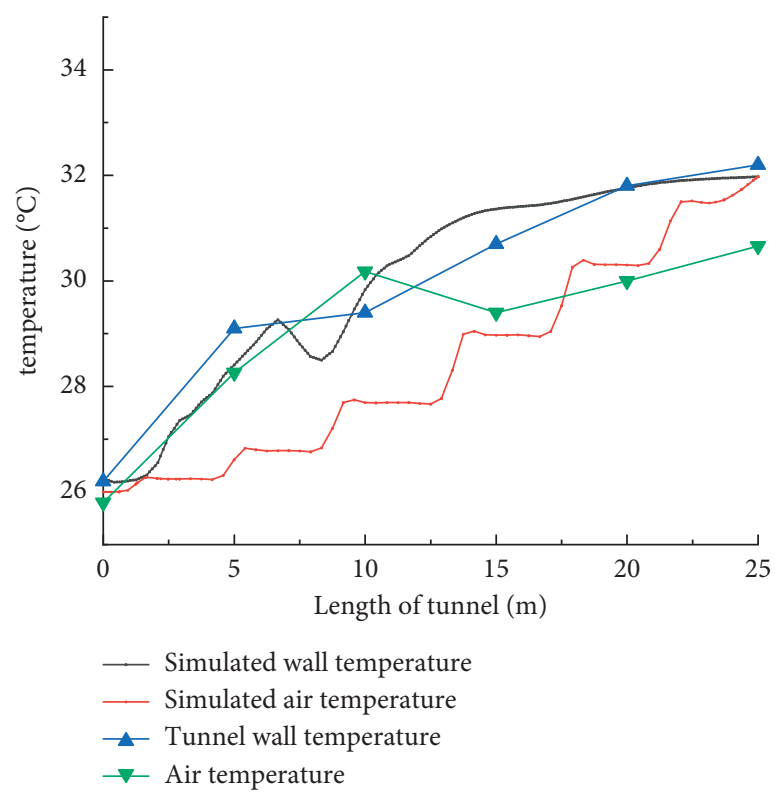

Figure 5: Comparison of simulated and measured temperatures.

\section{$\mathrm{L}(1)=10 \mathrm{~m}$}

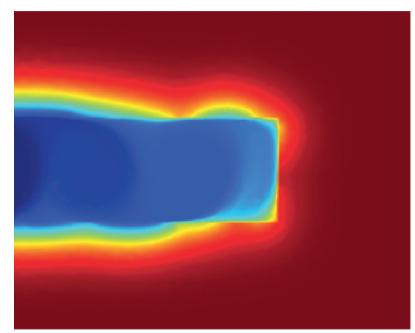

(a)

Figure 6: Continued. 
$\mathrm{L}(2)=20 \mathrm{~m}$
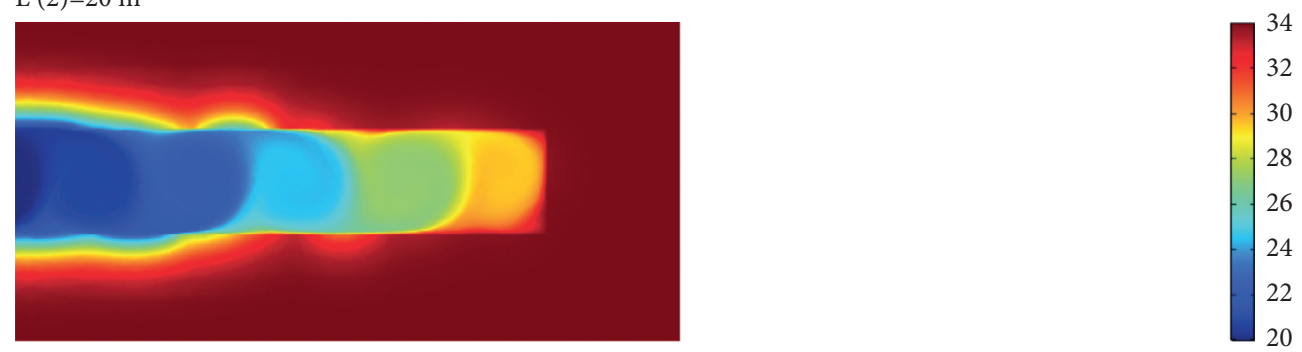

(b)

$L(3)=30 \mathrm{~m}$
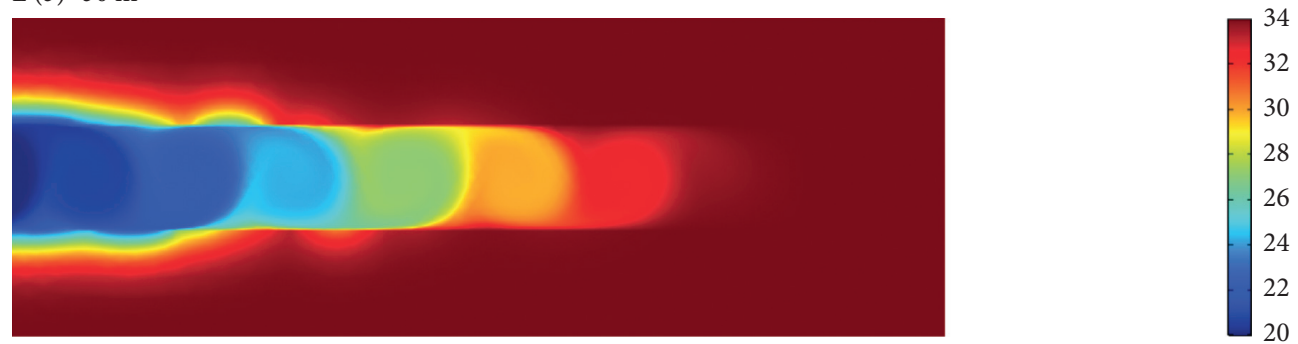

(c)

\section{$L(4)=40 \mathrm{~m}$}

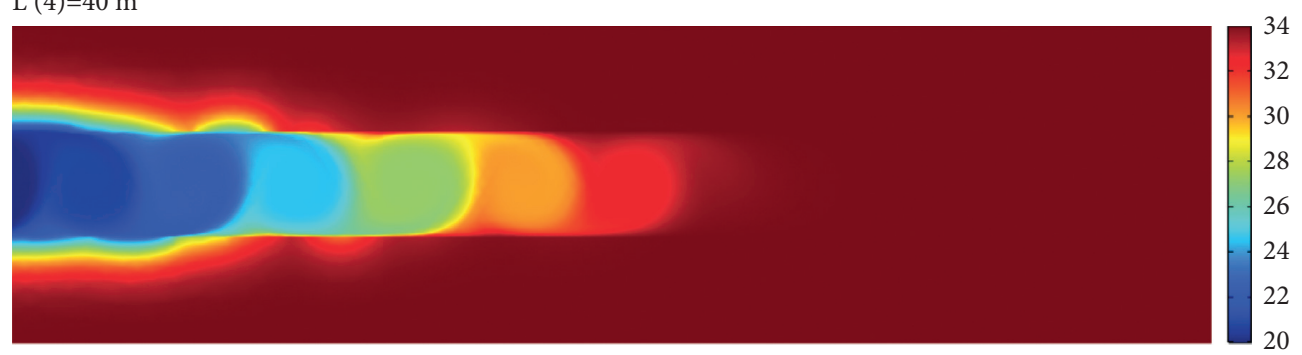

(d)

Figure 6: Temperature at different tunnel lengths (10-40 m) from the tunnel profile: (a) $L(1)=10 \mathrm{~m}$; (b) $L$ (2) =20 m; (c) $L$ (3) = $30 \mathrm{~m}$; (d) $L$ (4) $=40 \mathrm{~m}$.

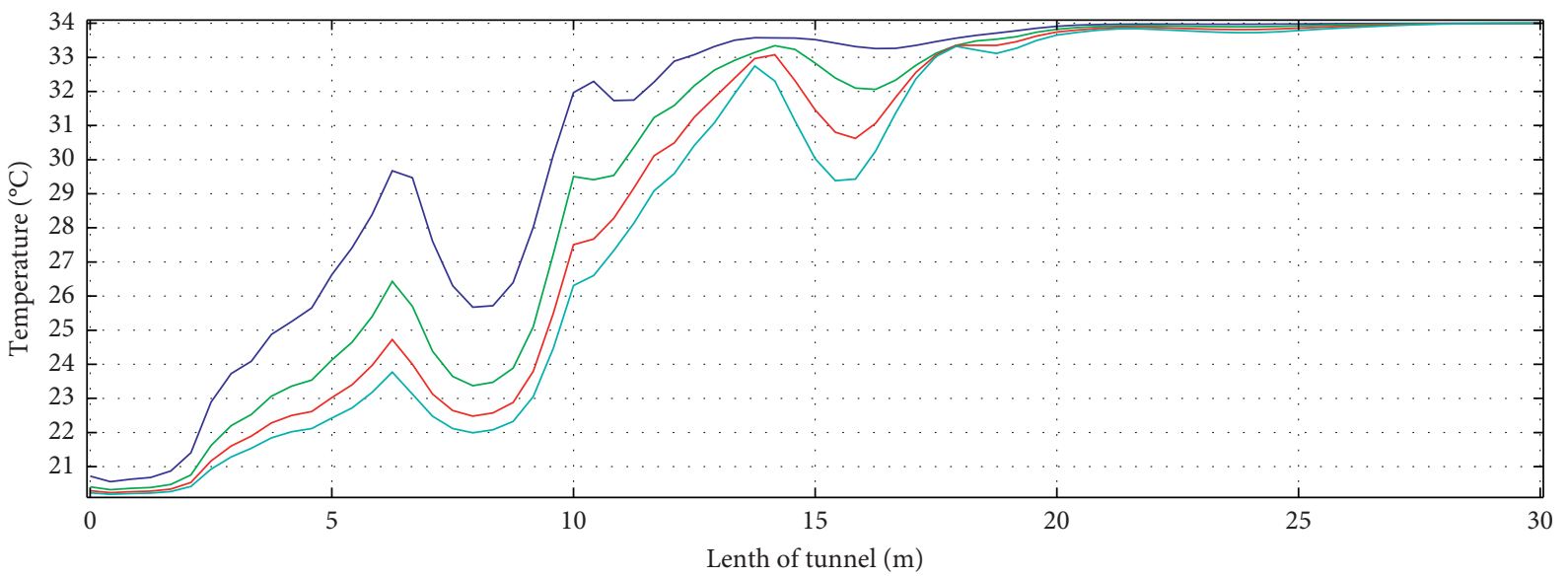

$\begin{array}{rl}\mathrm{v} 0=1 \mathrm{~m} / \mathrm{s} & -\mathrm{v} 0=3 \mathrm{~m} / \mathrm{s} \\ \mathrm{v} 0=2 \mathrm{~m} / \mathrm{s} & \mathrm{v} 0=4 \mathrm{~m} / \mathrm{s}\end{array}$

FIGURE 7: Temperature distribution on the wall surface at different wind speeds. 


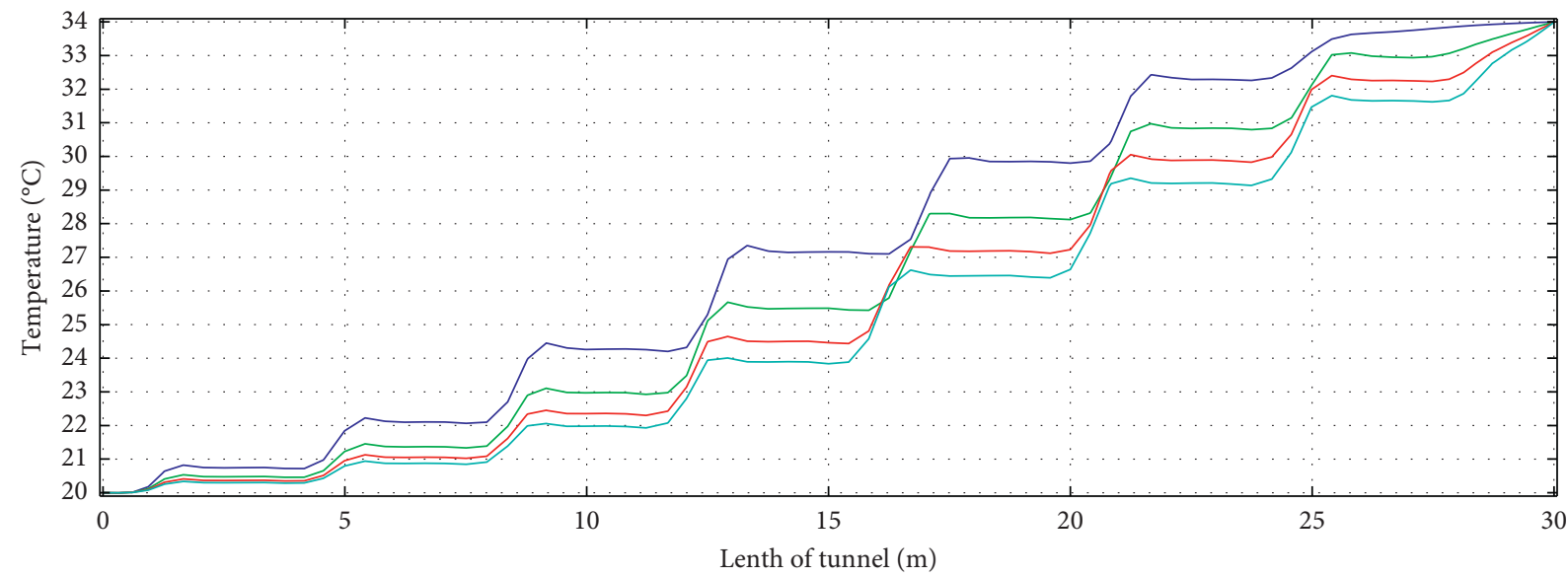
- $\mathrm{v} 0=1 \mathrm{~m} / \mathrm{s}$
- $\mathrm{v} 0=3 \mathrm{~m} / \mathrm{s}$
— $\mathrm{v} 0=2 \mathrm{~m} / \mathrm{s}$
$\mathrm{v} 0=4 \mathrm{~m} / \mathrm{s}$

FIGURE 8: Air temperature distribution inside the tunnel at different wind speeds.

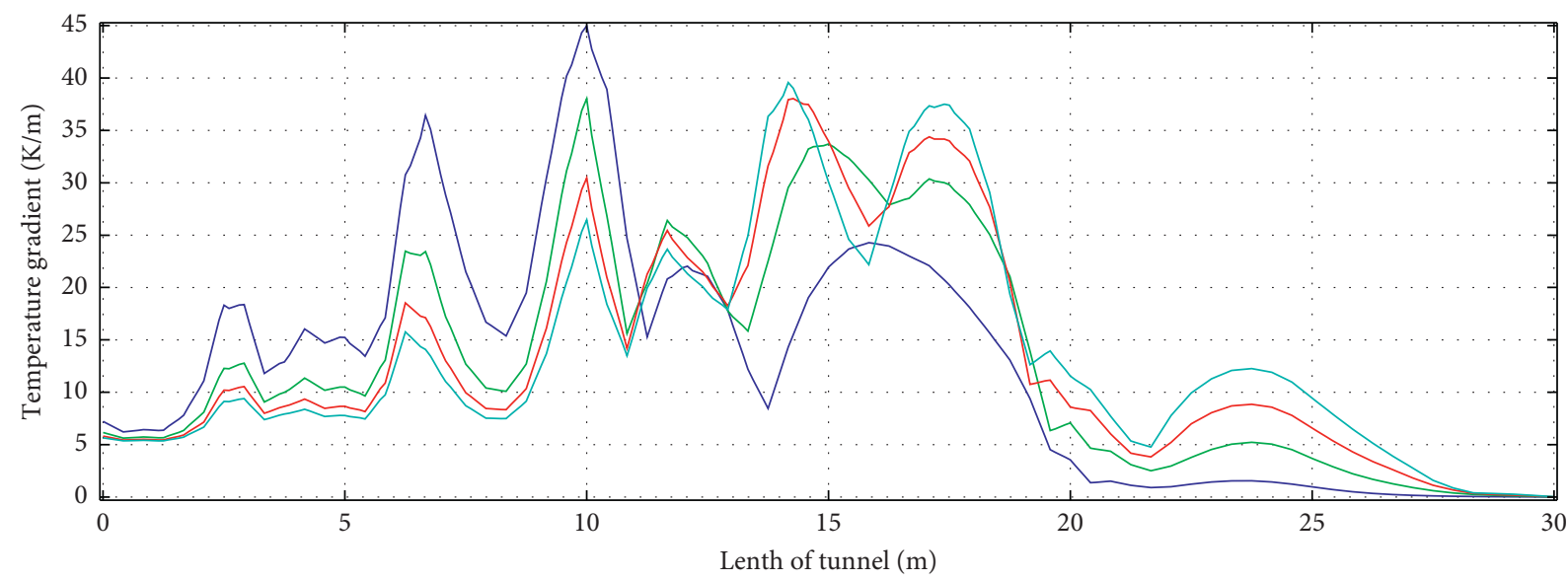

$\begin{array}{rl}-\mathrm{v} 0=1 \mathrm{~m} / \mathrm{s} & -\mathrm{v} 0=3 \mathrm{~m} / \mathrm{s} \\ \mathrm{v} 0=2 \mathrm{~m} / \mathrm{s} & \mathrm{v} 0=4 \mathrm{~m} / \mathrm{s}\end{array}$

FIGURE 9: Gradient of air temperature distribution inside the tunnel at different wind speeds.

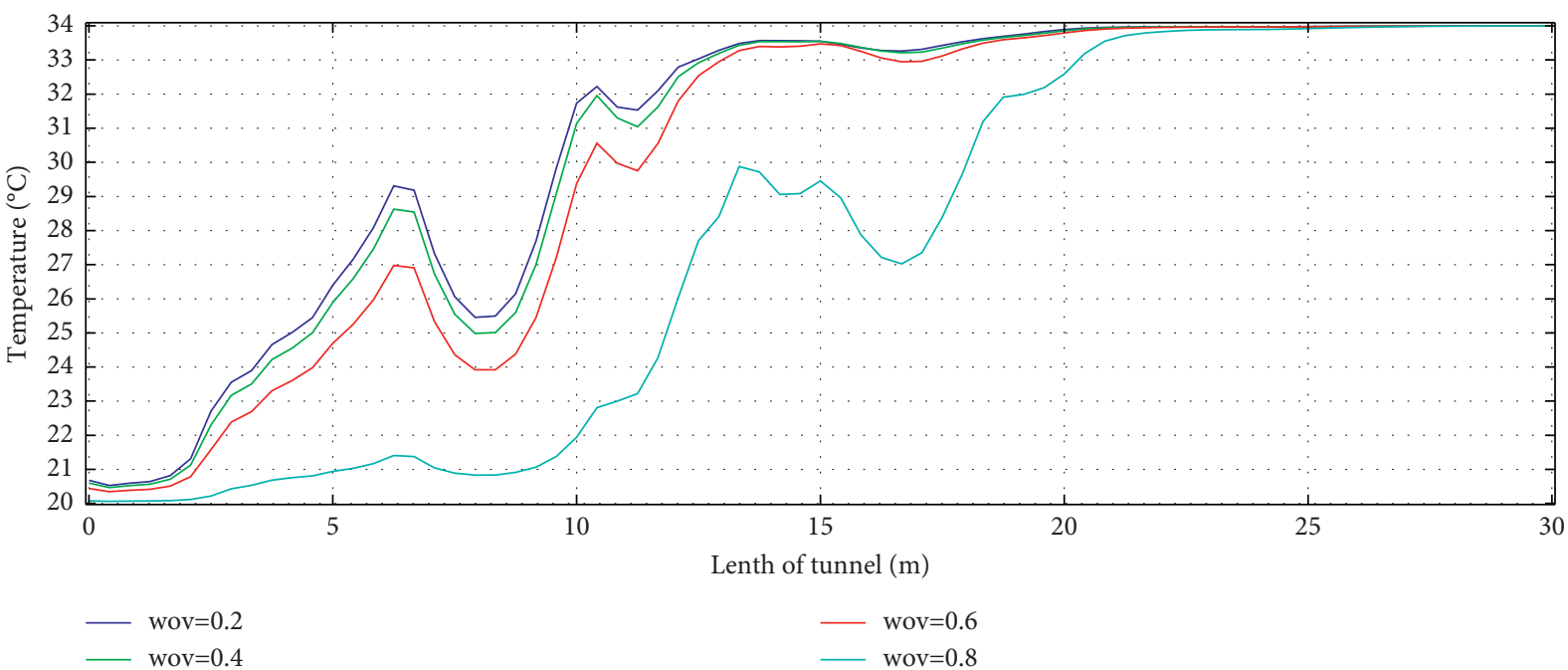

FIGURE 10: Temperature distribution of wall surface under different humidity. 


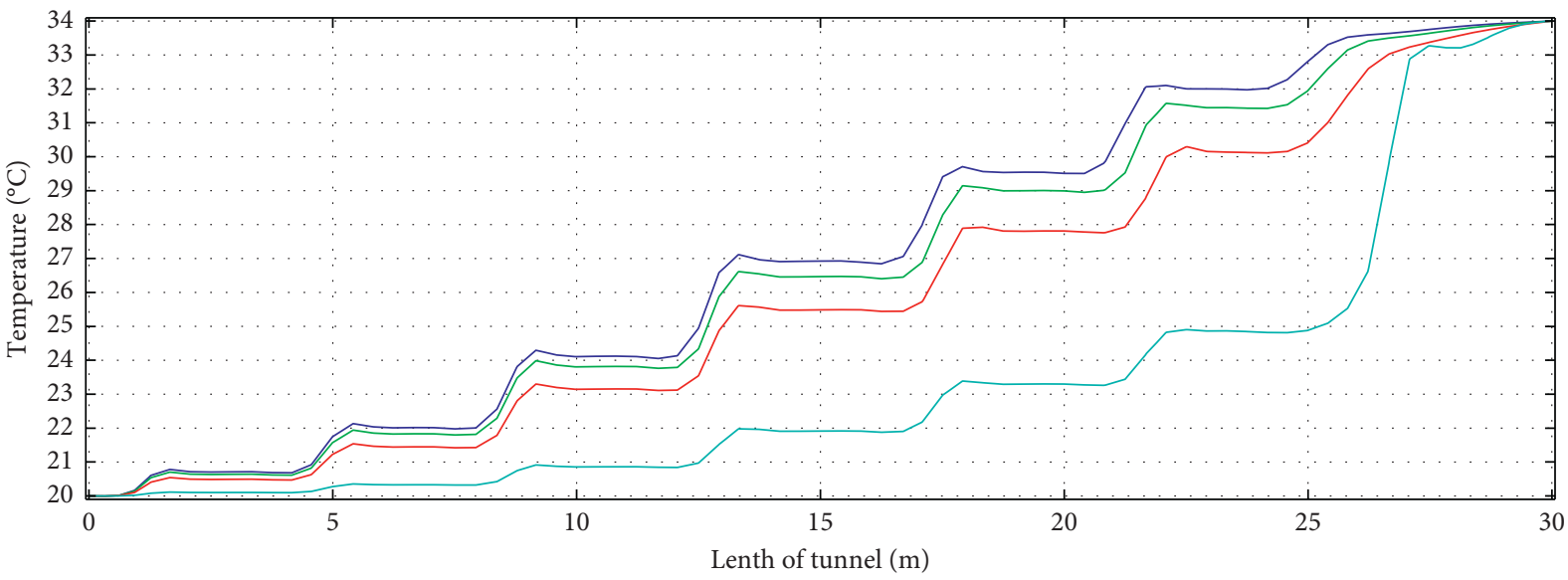

Figure 11: Air temperature distribution inside the tunnel under different humidity.

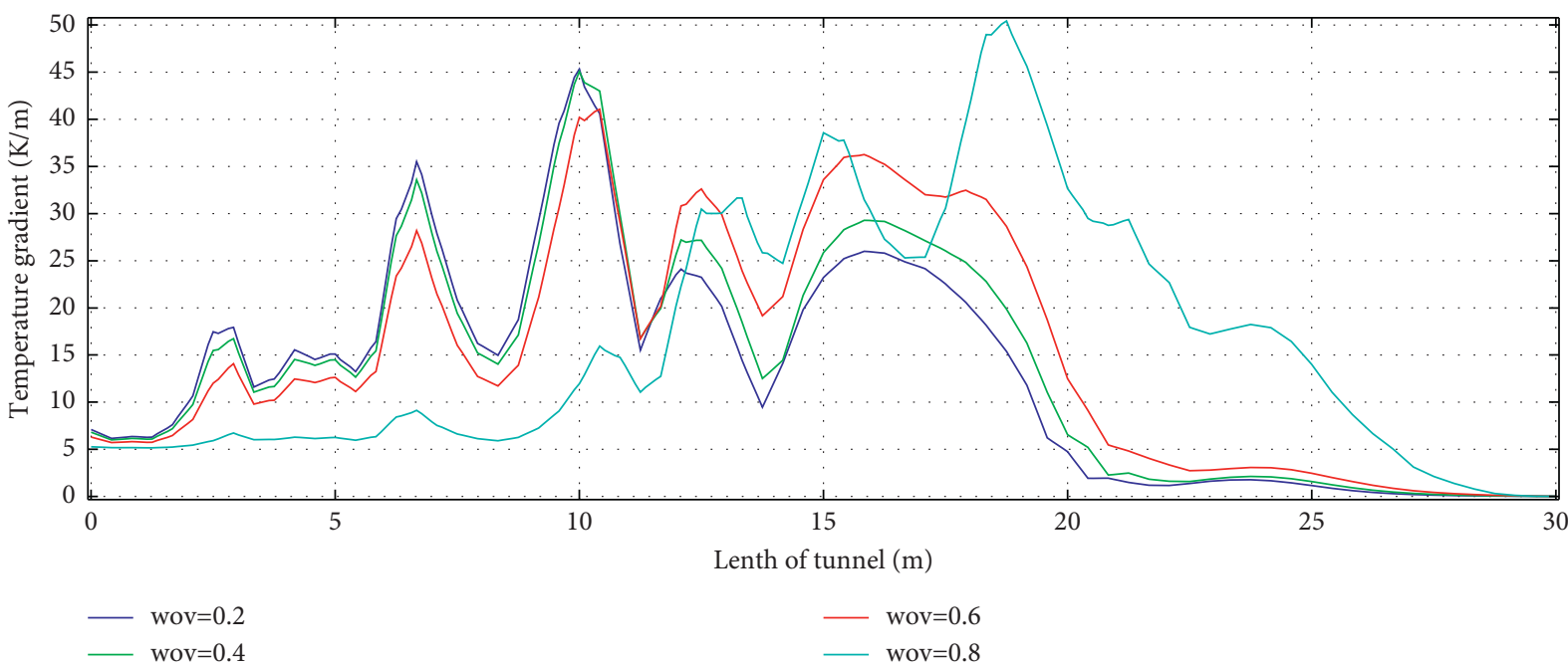

FIgURE 12: Gradient of air temperature distribution inside the tunnel under different humidity.

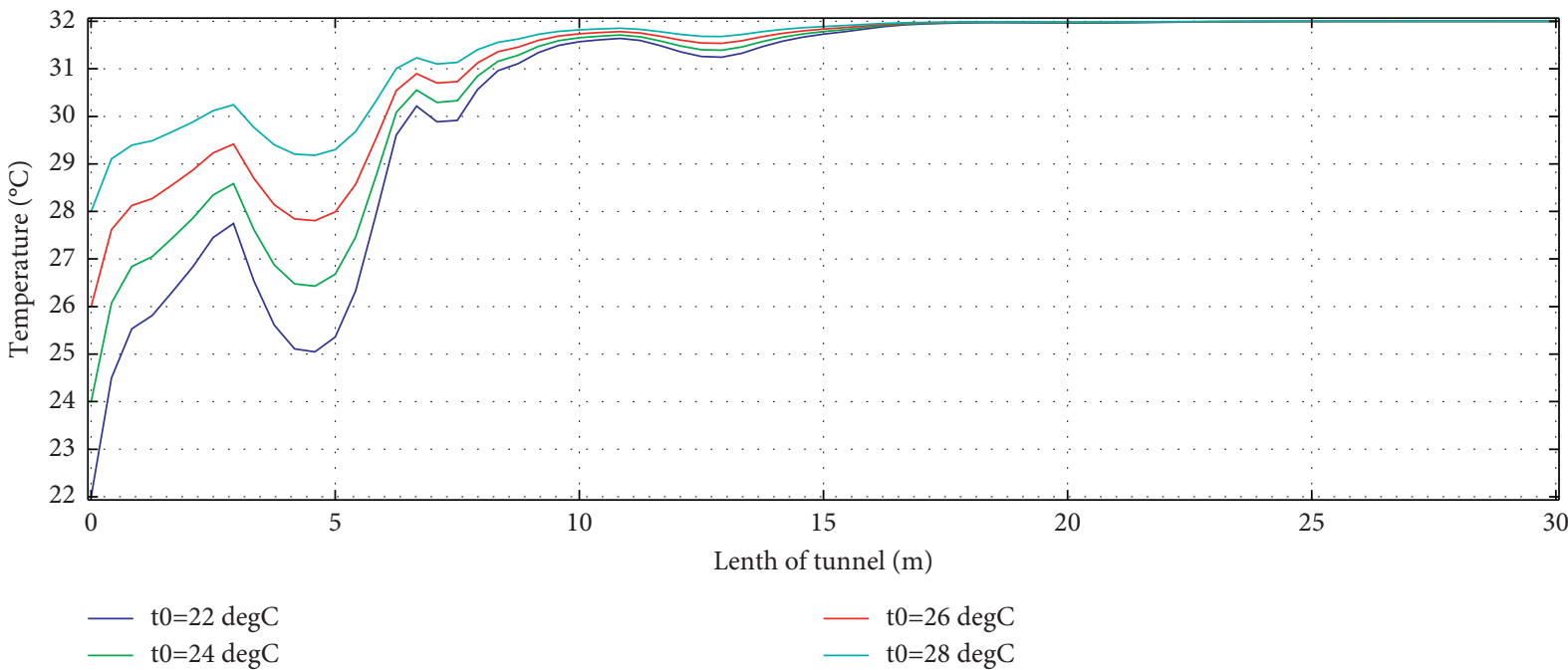

FIgURE 13: Wall surface temperature distribution at different air temperatures. 


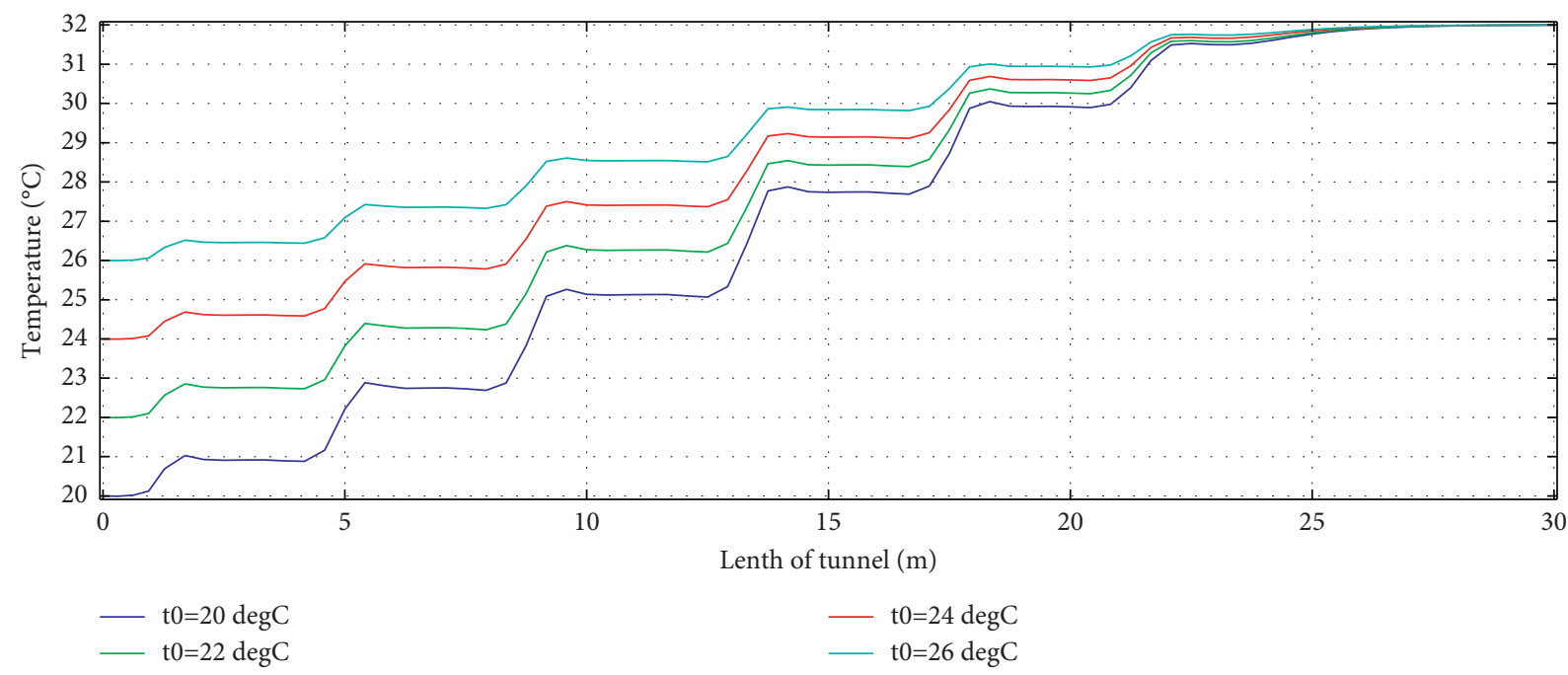

FIgURE 14: Air temperature distribution inside the tunnel at different air temperatures.

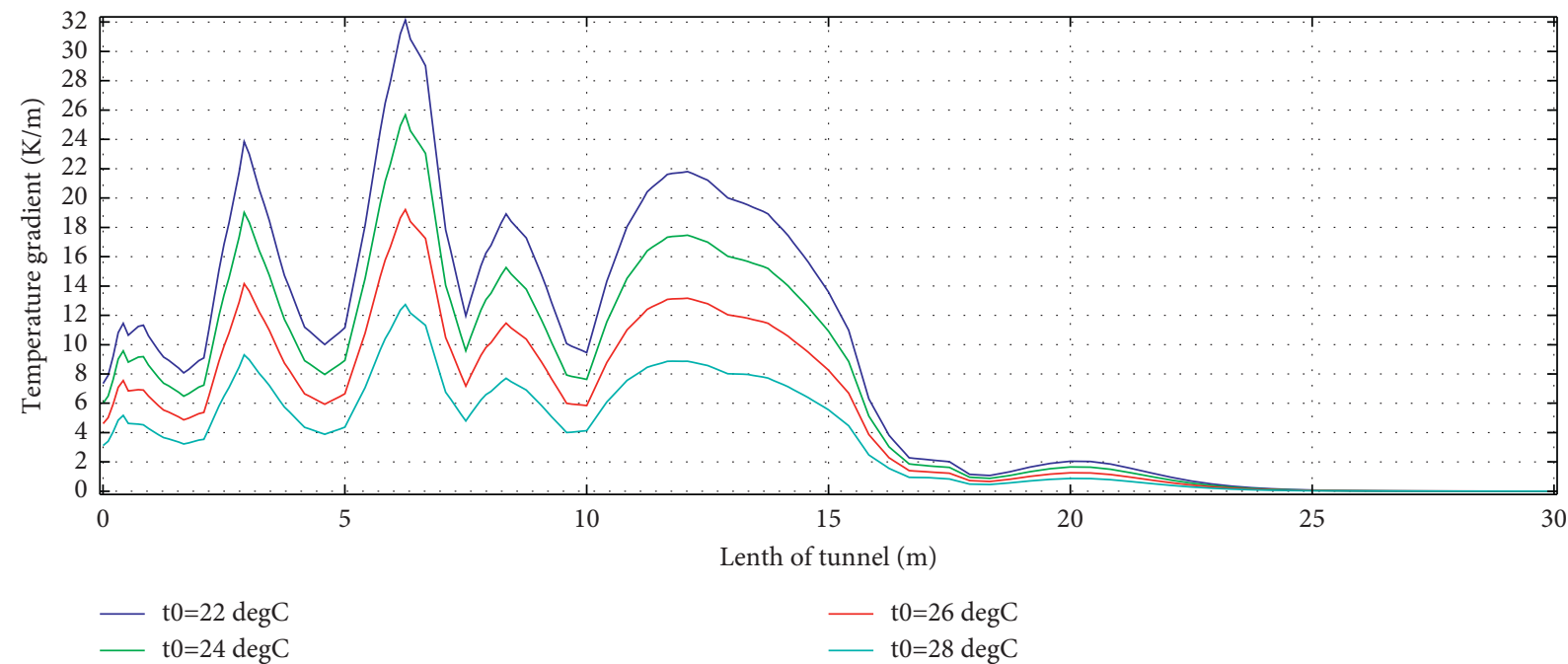

FIgURE 15: Gradient of air temperature distribution inside the tunnel at different air temperatures.

temperature field is more direct, and reducing the air temperature is the most obvious for reducing the temperature of the quarry.

\section{Conclusions}

(1) In this paper, the influence of mineral composition, tunnel length, wind speed, wind temperature, and wet air on the temperature field is analyzed in detail in the context of the deep mining area of Sanshandao gold mine, where the air temperature has the strongest influence on the temperature field and the tunnel length has the weakest influence.

(2) The increase in the length of the tunnel did not increase the heat exchange efficiency between the rock wall and the air, with a limit heat exchange distance of about $25-30 \mathrm{~m}$ at a wind speed of $1 \mathrm{~m} / \mathrm{s}$. The effect of air temperature on the temperature field is more direct than the effects of velocity and humidity on the temperature field; lowering the air temperature is the most evident way to lower the temperature of the quarry.

(3) The greater the wind speed velocity, the smaller the temperature gradient at the entrance of the tunnel and the greater the temperature gradient deeper in the tunnel. When entering the depth of the tunnel, the heat transfer efficiency decays, and when the flow velocity is $3 \mathrm{~m} / \mathrm{s}$ and $4 \mathrm{~m} / \mathrm{s}$, the effect of the increase in wind speed on the temperature field is already very limited. When the mass fraction of steam is greater than 0.6 , the heat exchange between the rock wall and the air increases substantially. 


\section{Data Availability}

The data included in this study are available from the corresponding author upon request.

\section{Conflicts of Interest}

The authors declare that there are no conflicts of interest regarding the publication of this paper.

\section{Acknowledgments}

This work was supported by the Key Research Development Program of Shandong Province, China (2019SDZY05), the National Natural Science Foundation of China (51774021 and 52074021), and Fundamental Research Funds for the Central University (FRF-GF-20-01B).

\section{References}

[1] W. Guo, X. Tu, R. Yao, and W. Li, "Research on thermal insulation materials for deep shaft coal mine tunnel," Coal Science and Technology, vol. 12, pp. 23-27, 2003.

[2] W. Chun Lai, C. Zeng, L. Ze Feng et al., "Erratum to: experimental investigation on predicting precursory changes in entropy for dominant frequency of rockburst," Journal of Central South University, vol. 28, no. 3, 2021.

[3] P. Roghanchi, K. C. Kocsis, and M. Sunkpal, "Sensitivity analysis of the effect of airflow velocity on the thermal comfort in underground mines," Journal of Sustainable Mining, vol. 15, no. 4, pp. 175-180, 2016.

[4] M. Krarti and J. F. Kreider, "Analytical model for heat transfer in an underground air tunnel," Energy Conversion and Management, vol. 37, no. 10, pp. 1561-1574, 1996.

[5] C. C. Xia, G. Z. Zhang, and X. G. Xiao, "Analytical solution to temperature fields of tunnel in cold region considering lining and insulation layer," Chinese Journal of Rock Mechanics and Engineering, vol. 29, no. 9, pp. 1767-1773, 2010, in Chinese.

[6] S. Xin, W. Wang, C. Zhang, C. Li, H. Li, and W. Yang, "Effects of rock-airflow conjugated heat transfer in development headings: a numerical study," International Journal of Thermal Sciences, vol. 172, Article ID 107301, 2022.

[7] X. Zhou, X. Ren, X. Ye, L. Tao, Y. Zeng, and X. Liu, “Temperature field and anti-freezing system for cold-region tunnels through rock with high geotemperatures," Tunnelling and Underground Space Technology, vol. 111, Article ID 103843, 2021.

[8] T. Lu, G. Zhang, S. Liu, B. Zheng, and X. Zhang, "Numerical investigation of the temperature field and thermal insulation design of cold-region tunnels considering airflow effect," Applied Thermal Engineering, vol. 191, Article ID 116923, 2021.

[9] L. Liu, Z. Li, X. Liu, and Y. Li, "Frost front research of a coldregion tunnel considering ventilation based on a physical model test," Tunnelling and Underground Space Technology, vol. 77, pp. 261-279, 2018.

[10] H. Fuk, "Drekopt. GluckaufBd," 9Bd, vol. 60, 1923.

[11] R. Nottrot and C. Sadee, "AbkuhlunghomogenenisotropenGesteins um einezylindrischestreckedurch wetter von Konstanter Temperature," Glückauf-Forschungshefte, vol. 27, p. 193, 1966.
[12] M. K. Lai, "Study on the distribution law of temperature field in the surrounding rock of deep shaft tunnel," Shanxi Construction, vol. 36, no. 12, pp. 89-90, 2010.

[13] Q. Zhang, Y. Gao, J. Li, X. Yuan, J. Zhao, and Z. Li, "Characteristics and influencing factors of temperature field response of surrounding rocks near water-bearing structures," Journal of Shandong University, vol. 3, pp. 72-77, 2011.

[14] S. Zhu, S. Wu, and S. Zhu, "Analysis and actual measurement of the thickness of the heat-regulating ring in the tunnel surrounding rock," Coal Technology, vol. 36, no. 5, pp. 142145, 2017.

[15] C. Guo, Y. W. Li, and G. B. Yan, "Numerical simulation analysis of heat transfer in the heat-regulating circle of the tunnelsurrounding rock," Science and Technology Outlook, vol. 26, no. 24, pp. 134-135, 2016.

[16] Y. He, W. Zhao, and G. Zhang, "Experimental study on the effect of temperature on thermal conductivity of granite and sandstone," China Testing, vol. 39, no. 1, pp. 114-116, 2013.

[17] C. Chen, C. Zhu, B. Tang, and T. Chen, "Progress in the study of factors influencing the thermal conductivity of rocks," Advances in Geophysics, vol. 1-18, 2020, http://kns.cnki.net/ kcms/detail/11.2982.P.20200608.0950.018.html.

[18] S. Zhu, S. Wu, and S. Zhu, "ABAQUS-based numerical simulation and economic evaluation of temperature distribution in the heat-regulating circle of the tunnel perimeter rock," Coal Mine Safety, vol. 48, no. 4, pp. 188-190+194, 2017. 